\title{
Determining the Effect Rate of Speed, Volume of Passenger Cars, Heavy Vehicles and Light Non-Passenger Car Vehicles on Likelihood of Accidents on Urban Highways
}

\author{
Mansour Hadji Hosseinlou, Ehsan Abbasi \\ Department of Civil Engineering, KN Toosi University of Technology, Tehran, Iran \\ Email: ehsan.abbasi395@gmail.com
}

How to cite this paper: Hosseinlou, M.H. and Abbasi, E. (2019) Paper Title. Open Journal of Safety Science and Technology, 9, 37-60.

https://doi.org/10.4236/ojsst.2019.92004

Received: March 25, 2019

Accepted: May 12, 2019

Published: May 15, 2019

Copyright $\odot 2019$ by author(s) and Scientific Research Publishing Inc. This work is licensed under the Creative Commons Attribution International License (CC BY 4.0).

http://creativecommons.org/licenses/by/4.0/

\begin{abstract}
In this article, the role of speed and volume of traffic on occurrence of accidents on urban highways is investigated using Fuzzy models and the accident data of Tehran urban highways is used as case study. To fuzzify the variables in scatter diagram, the notion of statistical percentiles is used for assigning the linguistic terms. To produce rules in each model, one or more variables are deemed effectively in occurrence of accidents. The evaluated number of accidents by developed models is compared with the number of observed accidents. The results of comparison represent the accuracy of each model. The model with the highest value of $R^{2}$ is the best model and the variables deemed effective for that model are those which do play a role in occurrence of accidents. Comparing the effect of elements of traffic volume indicates that after the average speed, volume of light non-passenger car vehicles is more effective on occurrence of accidents on urban highways than volume of heavy vehicles and passenger cars. After that the part of volume of heavy vehicles is more prominent than volume of passenger cars in the likelihood of more severe accident. The opposite is true for no injury accidents. After prioritization of variables in terms of influence on occurrence of accidents, the authors employed the models best fitting the data with the highest value of goodness of fit to do the sensitivity analyse. Sensitivity analyse specifies the effect rate of each variable on likelihood of accidents.
\end{abstract}

\section{Keywords}

Accidents, Urban Highways, Fuzzy Models, Speed, Light Non-Passenger Car

Vehicles, Sensitivity Analysis 


\section{Introduction}

The volume of traffic is comprised of different elements which could be categorized in three groups i.e. passenger cars, heavy vehicles including minibuses, buses, trucks and trailers and light non-passenger car vehicles including taxis, pickups and motorcycles. The role of elements of traffic volume in likelihood of property and more severe crashes in roads safety is investigated in different researches through different statistical and mathematical methods [1]-[9] (Chen et al., 2011; Ayati and Abbasi, 2011; Kaplan and Prato, 2012; Chang and Chien, 2013; Feng et al., 2016; Green et al., 2016; Castillo-Manzano et al., 2016; Tseng et al., 2016; Cerezo and Conche, 2016). The part of heavy vehicles in various segments of urban and rural roads network is studied many times more than the other elements of traffic volume. Furthermore, the influence of the presence of heavy vehicles in traffic flow on road safety has been studied in different methods.

Recently, Fuzzy Logic based models have been known as a perfect and powerful tool for modeling processes, which are complex with conventional quantitative techniques, or when the acquired information from modeling processes is qualitative, ambiguous or indefinite. Now Fuzzy Logic is used widespreadly for developing models and dealing with complicated systems.

Goh et al., (2014) conducted an analysis of bus-involved accident data to assess the safety impact of introducing bus priority measures in Metropolitan Melbourne, Australia. They developed two models; mixed-effects negative binomial and neural network based on the back-propagation approach to explore key traffic, transit and route factors associated with bus accident frequency. The results of mixed-effects negative binomial model indicated that bus accident frequency increases with traffic volume, route length, service frequency and stop density [10].

Cerezo and Conche (2016) studied the risk of accident occurrence of heavy vehicles in ramps. They used statistics from several accidents databases to investigate whether ramps were more risky for heavy vehicles and to specify the critical slope which found to be 3.2\%. Furthermore, simulations showed that heavy vehicles must drive more than $1000 \mathrm{~m}$ on ramps to reach their minimum speed and when the slope is superior to $3.2 \%$, tractor semi-trailer presents a strong decrease of their speed until $50 \mathrm{~km} / \mathrm{h}$. This situation represents a high risk of collision with other road users which drive at $80-90 \mathrm{~km} / \mathrm{h} \mathrm{[9]}$.

Chang and Chien (2013) developed a non-parametric Classification and Regression Tree (CART) model to develop the empirical relationship between injury severity results and driver/vehicle characteristics, highway geometric factors, environmental features, and accident variables. The results of their research showed that drinking-driving, seatbelt use, vehicle and collision type, contributing circumstance and driver/vehicle action, number of vehicles involved in the accident and accident location were the most effective factors of injury severity outcomes in truck accidents [4]. 
The safety problem of heavy vehicles has ever been of important concern for managers and officials of road safety and community, and has involved many researchers of traffic safety area such as Grytnes et al., 2016 [11]; Evgenikos et al., 2016 [12]; Boyce, 2016 [13]; Zhu and Srinivasan, 2011 [14]. In researches on traffic safety, researcher intends to predict traffic crashes due to potential conflict situation regarding road geometry, traffic volume composition, weather condition, drivers' characteristics or behaviors. Such intention usually appears in format of a model which relates various potential factors to output variable that is normally number or likelihood of accidents both property or more severe accidents.

Recent scholars have utilized different methods to investigate the road safety under flow of heavy vehicles. Part of them studied the operational features and design criterions to predict factors affecting the road safety among many potential factors that each scholar studied on and concluded about its effect. This methodology intends to assess the dimension and elements of heavy vehicles performance on urban or rural highways to let them drive on roads facilitated with standard geometry [15] [16] [17] [18] (Abdelwahab and Abdel-Aty, 2004; Daniel and Chien, 2004; Mohamed et al., 2012; Edwards et al., 2014).

Hosseinpour et al. (2014) found out in their study on occurrence of head-on accidents on federal roads in Malaysia that variables horizontal curvature, terrain type, heavy-vehicle traffic, and access points positively influence on the frequency of head-on accidents, while posted speed limit and shoulder width decreased the accident frequency. Also horizontal curvature, paved shoulder width, terrain type, and side friction have significant impact on more severe accidents, whereas land use, access points, and presence of median reduced the probability of severe accidents [19].

Mussone et al. (2017) in their research estimated the level of accident severity at intersections using environmental and traffic factors through a back propagation neural network model and the generalized linear mixed model that used an analytical approach. Counting passing flow shows the number of conflicts (potential accident) occurs on road intersections under study [20]. Rusli et al. (2017) investigated the frequency of single vehicle accidents in terms of geometric factors comprising horizontal and vertical curves, traffic flow related factors, weather condition, cross-sectional factors, and roadside features. Results of their research implied that rainfall during the accident is positively associated with single vehicle accidents, but real-time visibility is negatively associated. The presence of a road shoulder along mountainous highways is associated with less number of single vehicle accidents [21].

Tseng et al., 2016 explored the factors that lead to violation from speed limit for large truck drivers of Taiwan. The results of their research indicated that the factors which influenced speeding offense were not related to job experience. Rather, the driver's demographics including age and education, mental condition i.e. sleep quality, and driving status i.e. yearly distance driven and driving 
late at night were significantly associated with violation from speed limit [8]. Mallia et al. (2015) in their study used a personality-tendencies model to estimate if personality traits are associated with improper self-reported driving behaviors both directly and indirectly, through the effects of attitudes towards traffic safety in a large sample of bus drivers. Structural equation modeling analysis revealed that personality traits were associated to aberrant driving behaviors. Personality traits related to emotionality were directly associated with bus drivers' aberrant driving behaviors, without interference of tendencies [22].

Fowles et al. (2013) studied the effect of cell phones on truck accident rates. Cell phones were found to have a significant effect on these rates. A nonlinear model was evaluated by a set of exact specification requirements. The model suggested a non-linear impact of cell phone usage on truck accident rates. Hence, cell phones have a positive effect on crashes but at a decreasing rate [23].

Chen et al. (2016) examined in their research the sleep patterns of $96 \mathrm{com}$ mercial truck drivers during non-work periods and evaluated the influence the sleep patterns had on truck driving performance. Negative binomial regression was used to evaluate the relationship between the sleep patterns and driving performance, compatible with driver demographic data. The results of their research indicated that the sleep pattern with the highest safety-critical event rate was related to shorter sleep; sleep in the early stage of a non-work period, and less sleep between 1 a.m. and 5 a.m. Also male drivers, with fewer years of commercial vehicle driving experience and higher body mass index, were related to nonsense driving performance and increased driving risk [24].

Keeping a proper level of friction is a crucial maintenance practice, because of the effect it has on roadway safety. Najafi et al. (2016) came up with a fuzzy logic inference system in their research to predict the rate of vehicle crashes based on traffic level, speed limit, and surface friction. Mamdani and Sugeno fuzzy controllers were used to develop the model. The results of research provided a decision support model for highway agencies to monitor the network's friction and make sound judgments to remove flaws based on crash risk. Furthermore, the model could be implemented in the vehicle periphery to warn drivers of slippery locations in ice or rainy periods [25].

The accident data of Tehran urban highways in the period from 2010 to 2015 are used to model crashes on urban highways in this study. These data were gathered by the traffic and transportation organization of Tehran. For collecting the accident statistics, 100 kilometers of highways are divided into 100 parts with constant length equal to 1 kilometer. In addition, the number of crashes in each part is collected for different hours of the day which were divided into first traffic peak hours, second the day non-peak hours and third night non-peak hours. Thus there are 300 data available for 300 subparts.

The objective of this research is to determine the effect rate of speed, volume of passenger cars, heavy vehicles and light non-passenger car vehicles on likelihood of crashes on urban highways by separating the volume into three distinct 
groups i.e. passenger cars, heavy vehicles comprising minibuses, buses, trucks and trailers and light non-passenger car vehicles consisting taxis, pickups and motorcycles. To conduct so, MATLAT program, Fuzzy logic Toolbox is utilized. The stages of developing models include Fuzzification of input and output variables, Rule production, Composition or Aggregation of diagrams and Defuzzification. After developing the models for predicting the number of crashes on urban highways, the evaluated number of property and more severe crashes by the models are compared with the number of observed crashes for each combination of effective factors. The results of comparison represent the accuracy of each model which is developed based on the role of variables that considered effective in occurrence of property or more severe crashes individually. The model with highest value of $R^{2}$ is the best model and the variables considered effective for that model are the traffic flow related variables i.e. speed and three predefined categories of traffic volume that do play role in occurrence of property or more severe crashes. This technique of identification of effective factors on likelihood of traffic crashes is the main contribution of this article. The contribution goes further when the effect of these factors is ranked and it is specified that which variable is more effective than the other. Furthermore the researchers want to determine the impact rate of each factor on occurrence of crashes on urban highways. For this job sensitivity analysis is done, as the number of each effective factor is increased by one unit and the best model predict the rate of change in number of crashes.

\section{Methodology}

In this study, the fuzzy logic based models for modeling accidents on urban highways are developed based on the gathered data of accidents and independent variables. Fuzzy logic modeling is a four staged procedure including fuzzification of input and output variables, rule production, composition and aggregation of diagrams and defuzzification.

Linguistic terms low-medium-high are usually applied For developing Fuzzy models in modeling accidents and a part could be simultaneously the member of more than one fuzzy set. Information flow through a fuzzy model requires that the input variables go through three major transformations before exiting the system as output information, which are known as fuzzification, rule production, composition and aggregation and defuzzification. After fuzzification of input and output variables and establishing the rules based on the role of variables deemed effective in accident occurrence, the composition of diagrams is processed. The next step is defuzzification for obtaining the crisp output from assembled fuzzy output. For so, the Centroid method is applied. In this method, the center of area of the aggregation diagram is calculated. This centroid is the crisp output that is the number of predicted accidents. Through a similar process, for all values of volume and speed, the number of accidents is predicted. For doing calculations, MATLAB program, the Fuzzy Toolbox is utilized. 


\subsection{Fuzzification of the Variables}

Fuzzification encompasses two stages; obtaining the membership functions for input and output variables and linguistic depicting of these functions. Triangular and trapezoidal membership functions are applicable for modeling accidents with great deal of variations. Statistics of the accidents and independent variables of the models are gathered for 100 sections of Tehran urban highways in 300 subsections. The passenger car equivalent factors of vehicle types are given in Table 1 [26] (Transportation and Traffic Organization of Tehran, 2013):

The total volume (passenger car equivalent) of light non-passenger car vehicles and heavy vehicles is obtained by following equation:

$$
V_{t e}=e_{1} N_{1}+\cdots+e_{n} N_{n}
$$

where $V_{t e}$ is the total equivalent volume and $e_{i}$ and $N_{i}$ are equivalent factor and number of vehicles of type $i$ respectively.

The scatter diagrams of input and output variables are presented in Figure 1.

Based on the scatter diagram of speed, for fuzzification the percentiles $\mathrm{P}_{20}, \mathrm{P}_{40}$, $\mathrm{P}_{60}$ and $\mathrm{P}_{80}$ equal to $45,60,70$ and 90 are used and 4 fuzzy subsets defined. The fuzzified of the variable level of physical health of drivers is as the following diagram Figure 2.

Based on the scatter diagram of volume of passenger cars, for fuzzification the percentiles $\mathrm{P}_{17}, \mathrm{P}_{33}, \mathrm{P}_{50}, \mathrm{P}_{67}$ and $\mathrm{P}_{83}$ equal to $368,599,792,1147,1780$ are used and 5 fuzzy subsets defined. The fuzzified of the input variable volume of passenger cars is as the following diagram Figure 3.

Based on the scatter diagram of volume of heavy vehicles, for fuzzification the percentiles $\mathrm{P}_{17}, \mathrm{P}_{33}, \mathrm{P}_{50}, \mathrm{P}_{67}$ and $\mathrm{P}_{83}$ equal to 172, 292, 418, 580, 931 are used and 5 fuzzy subsets defined. The fuzzified of the input variable volume of heavy vehicles is as the following diagram Figure 4.

Based on the scatter diagram of volume of light non-passenger car vehicles, for fuzzification the percentiles $\mathrm{P}_{17}, \mathrm{P}_{33}, \mathrm{P}_{50}, \mathrm{P}_{67}$ and $\mathrm{P}_{83}$ equal to 212, 311, 448, 609,989 are used and 5 fuzzy subsets defined. The fuzzified of the input variable volume of light non-passenger car vehicles is as the following diagram Figure 5.

Based on the scatter diagram of number of no injury accidents, for fuzzification the percentiles $\mathrm{P}_{17}, \mathrm{P}_{33}, \mathrm{P}_{50}, \mathrm{P}_{67}$ and $\mathrm{P}_{83}$ equal to $0,2,4,8,13$ are used and 5 fuzzy subsets defined. The fuzzified of the output variable number of no injury accidents is as the following diagram Figure 6.

For the number of more severe accidents, the quartiles $\mathrm{P}_{25}, \mathrm{P}_{50}$ and $\mathrm{P}_{75}$ equal to 0,1 and 2 respectively are applied and 3 fuzzy subsets defined. The fuzzified diagram of the output variable number of more severe accidents is as following diagram Figure 7.

Table 1. The passenger car equivalent factors of vehicle types.

\begin{tabular}{cccccccc}
\hline $\begin{array}{c}\text { Heavy } \\
\text { vehicles }\end{array}$ & $\begin{array}{c}\text { Bicycle and } \\
\text { Motorcycle }\end{array}$ & $\begin{array}{c}\text { Intracity } \\
\text { bus }\end{array}$ & $\begin{array}{c}\text { Intercity } \\
\text { bus }\end{array}$ & Minibus & Pickup & Taxi & $\begin{array}{c}\text { Passenger } \\
\text { car }\end{array}$ \\
\hline 2.5 & 0.5 & 5 & 2.5 & 2 & 1 & 2 & 1 \\
\hline
\end{tabular}




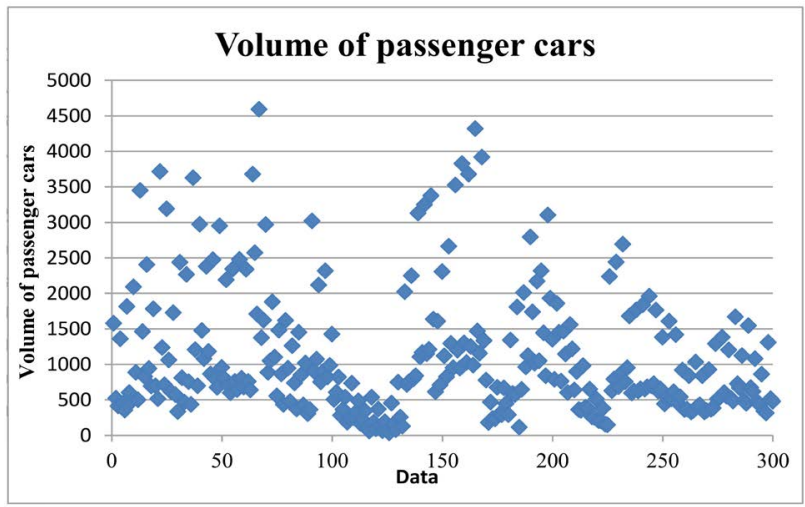

(a)

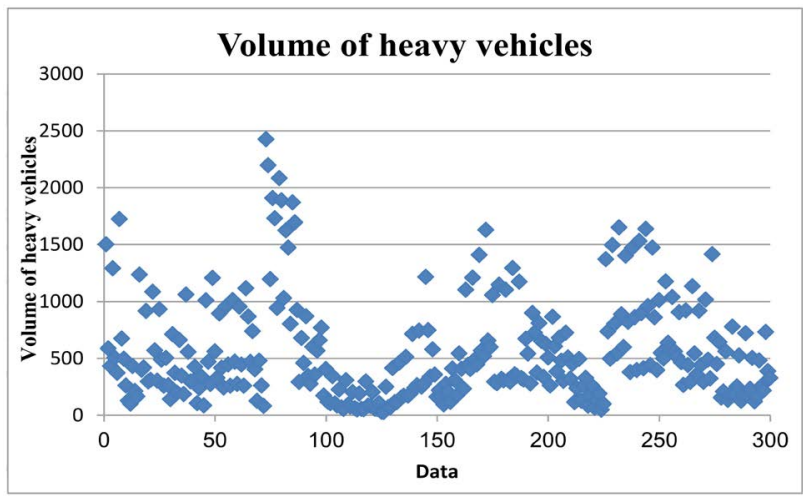

(b)

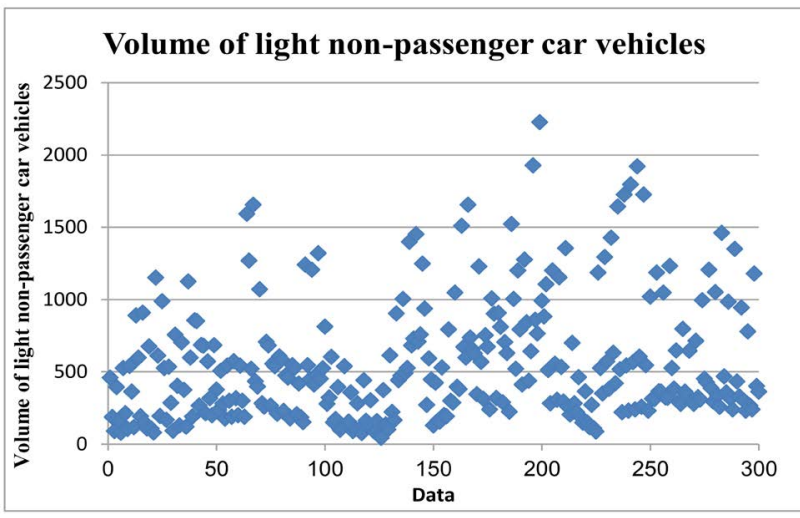

(c)

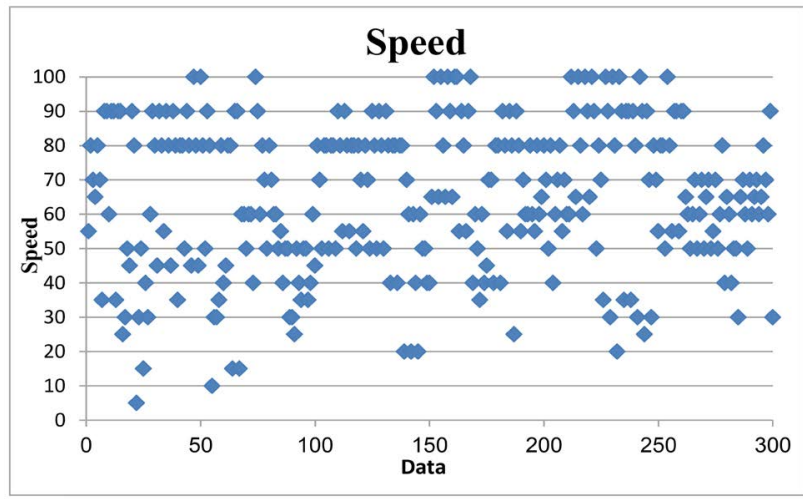

(d) 


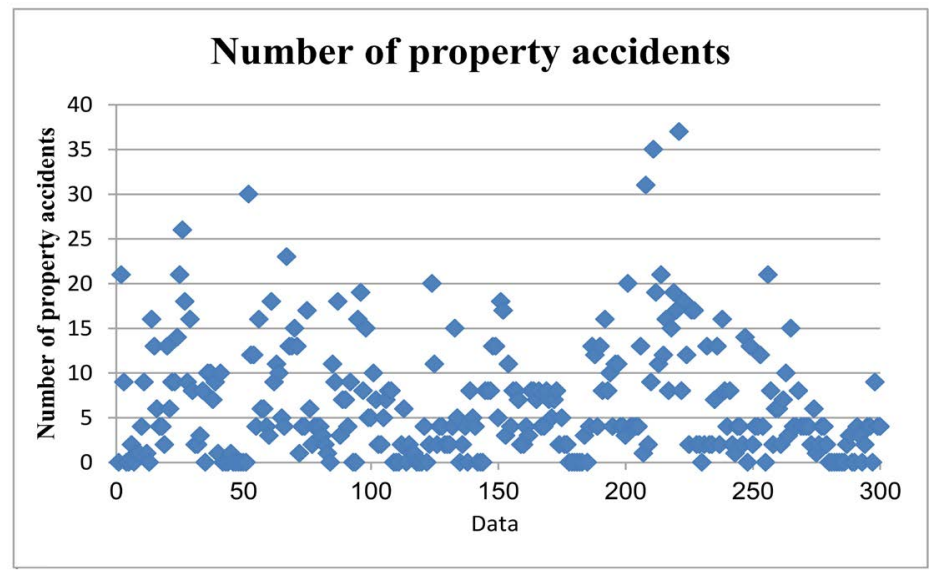

(e)

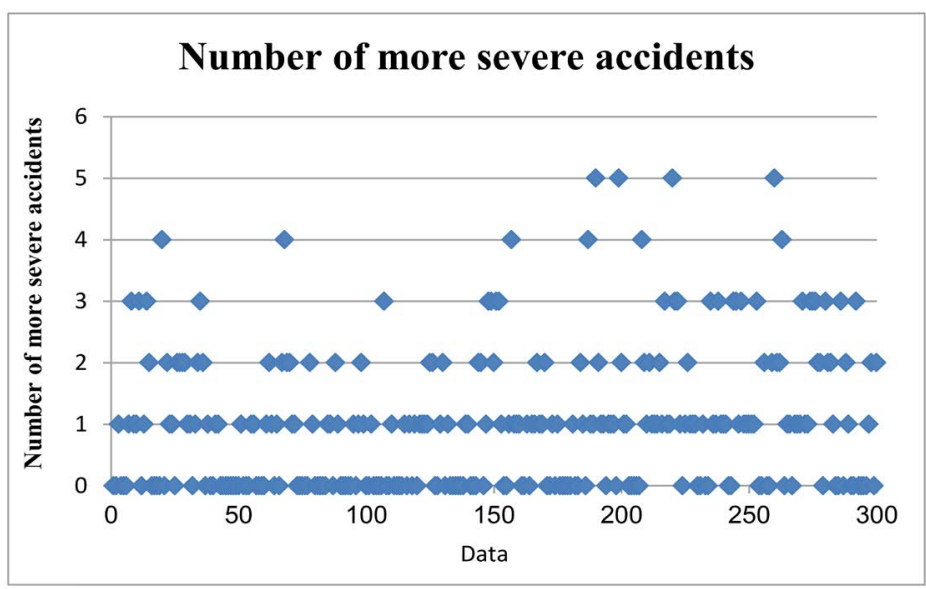

(f)

Figure 1. Scatter diagrams of input and output variables of fuzzy logic based models. (a) Scatter diagram of input variable volume of passenger cars; (b) Scatter diagram of input variable volume of heavy vehicles; (c) Scatter diagram of input variable volume of light non passenger car vehicles; (d) Scatter diagram of input variable speed; (e) Scatter diagram of output variable number of property accidents; (f) Scatter diagram of output variable number of more severe accidents.

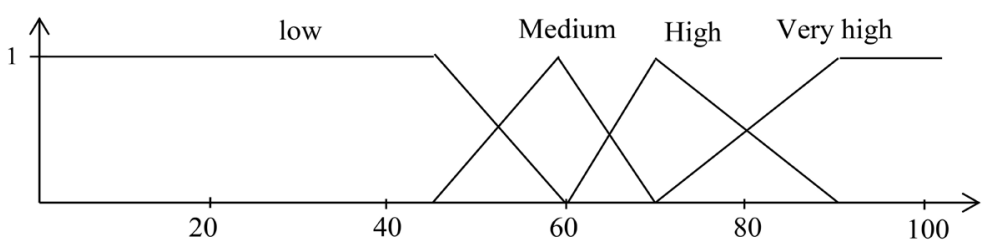

Figure 2. Fuzzification of the variable speed.

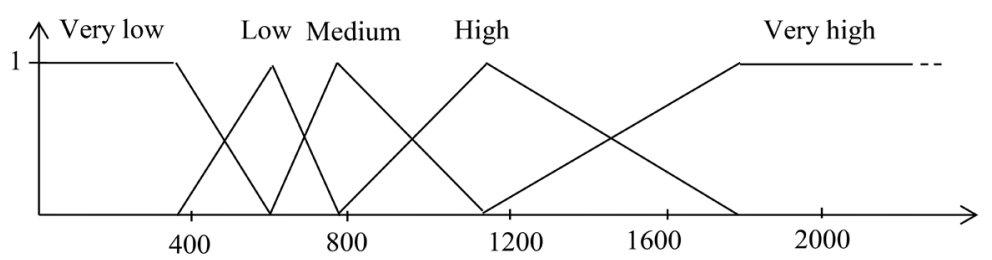

Figure 3. Fuzzification of the variable volume of passenger cars. 


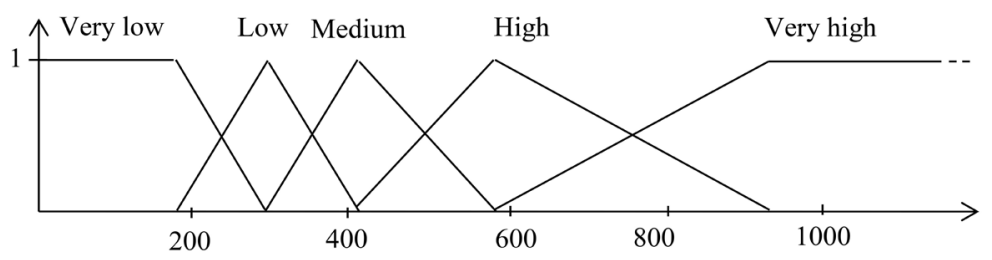

Figure 4. Fuzzification of the variable volume of heavy vehicles.

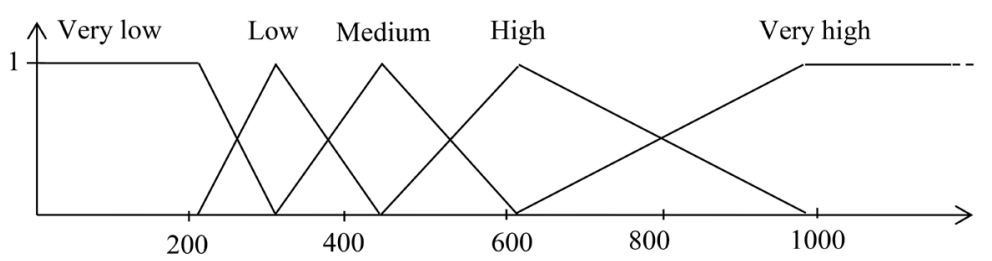

Figure 5. Fuzzification of the variable volume of light non-passenger car vehicles.

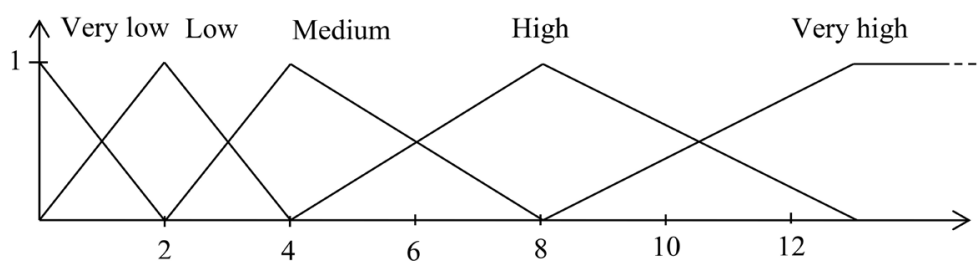

Figure 6. Fuzzification of the variable number of property accidents.

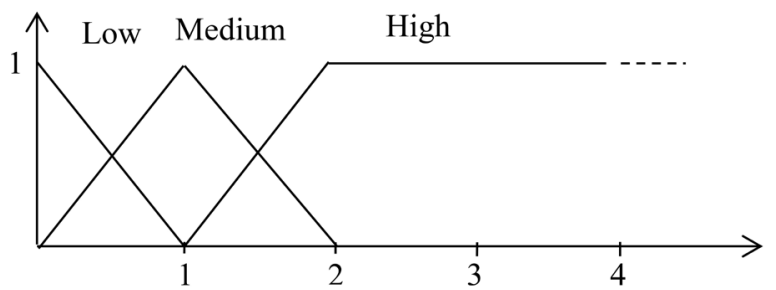

Figure 7. Fuzzification of the variable number of more severe accidents.

\subsection{Production of Rules}

After fuzzification of input and output variables, it is the turn for developing rules. There are several methods for producing rules. In this research the Mamdani method is applied. In this method for this research, there are 4 input variables including speed, volume of passenger cars, volume of heavy vehicles and volume of light non-passenger car vehicles with 4, 5, 5 and 5 fuzzy subsets respectively. Therefore $4 \times 5 \times 5 \times 5$ equal to 500 rules are producible. Producing rules depends on the factors deemed effective on the occurrence of accidents and type of the relationship i.e. direct or reverse. For instance, to start the modeling, the variable speed is deemed effective on the occurrence of property and more severe accident and the relationship is direct which indicates that the higher the speed, the higher the number of accidents, whether property or more severe accidents. If the other variables are ineffective on the occurrence of accidents the produced rules are as following:

1) If the speed is low, the number of accidents is low. 
2) If the speed is medium, the number of accidents is medium.

3) If the speed is high, the number of accidents is high.

4) If the level of physical health is very high, the number of accidents is very high.

In other steps, other variables could be considered effective alone or in combination, with direct or inverse effect. For example, if the variables speed and volume of light non-passenger car vehicles are considered effective is occurrence of accidents with direct effect, the rules are produced as following:

1) If the speed is low and volume of light non-passenger car vehicles is very low, the number of accidents is low or very low.

2) If the speed is low and volume of light non-passenger car vehicles is low, the number of accidents is low.

3) If the speed is low and volume of light non-passenger car vehicles is medium, the number of accidents is low or medium.

4) If the speed is low and volume of light non-passenger car vehicles is high, the number of accidents is medium.

5) If the speed is low and volume of light non-passenger car vehicles is very high, the number of accidents is medium or high.

17)If the speed is very high and volume of light non-passenger car vehicles is low, the number of accidents is low or medium.

18)If the speed is very high and volume of light non-passenger car vehicles is medium, the number of accidents is low.

19)If the speed is very high and volume of light non-passenger car vehicles is high, the number of accidents is low or very low.

20)If the speed is very high and volume of light non-passenger car vehicles is very high, the number of accidents is very low.

As stated above, for each combination of effective factors, the corresponding rules are producible.

\subsection{Aggregation and Defuzzification}

After fuzzification of input and output variables and producing rules, combination of diagrams is processed. Composition of diagrams is done according to the rules. After composition and aggregating the diagrams, the next step is defuzzification. In defuzzification, for each mixture of input variables and resulted aggregation diagram, the crisp output, that is the specified number of no injury or more severe accidents, is obtained using the method of centriod. For combination of diagrams and defuzzification, MATLAB software, Fuzzy Toolbox is applied. Accordingly, for each input data set, one specified number of property and more severe accidents is estimated by fuzzy logic based models. To clarify the method here are examples of input data set and method of calculation of output value for each data set: 
1) For the 50-th data, according to Scatter diagrams in Figure 1, the volume of passenger cars is $2213 \mathrm{pc} / \mathrm{h}$, volume of heavy vehicles is $1235 \mathrm{pc} / \mathrm{h}$, volume of light non-passenger car vehicles is $704 \mathrm{pc} / \mathrm{h}$ and speed is $50 \mathrm{~km} / \mathrm{h}$. Based on fuzzification diagrams of input variables in Figures 2-5, volume of passenger cars and heavy vehicles is very high, while volume of light non-passenger car vehicles is high/very high and speed is low/medium. If all input variables are considered effective (increasingly) in occurrence of property accidents as for case 4 in Table 2 (comes later as the best case) following rules are producible:

a) If volume of passenger cars and heavy vehicles is very high, volume of light non-passenger car vehicles is high and speed is low, the number of property accidents is high.

b) If volume of passenger cars and heavy vehicles is very high, volume of light non-passenger car vehicles is high and speed is medium, the number of property accidents is high.

c) If volume of passenger cars and heavy vehicles is very high, volume of light non-passenger car vehicles is very high and speed is low, the number of property accidents is very high.

d) If volume of passenger cars and heavy vehicles is very high, volume of light non-passenger car vehicles is very high and speed is medium, the number of property accidents is very high.

Table 2. The prediction power of number of property accidents of different cases.

\begin{tabular}{|c|c|c|c|}
\hline Case & $\begin{array}{l}\text { Effective factors } \\
\text { (considered) }\end{array}$ & Number of rules & $\mathrm{R}^{2}$ \\
\hline 1 & Speed & 4 & 0.53 \\
\hline 2 & $\begin{array}{l}\text { 1) Speed } \\
\text { 2) Volume of light non-passenger car vehicles }\end{array}$ & 20 & 0.63 \\
\hline 3 & $\begin{array}{l}\text { 1) Speed } \\
\text { 2) Volume of light non-passenger car vehicles } \\
\text { 3) Volume of heavy vehicles }\end{array}$ & 100 & 0.68 \\
\hline 4 & $\begin{array}{l}\text { 1) Speed } \\
\text { 2) Volume of light non-passenger car vehicles } \\
\text { 3) Volume of heavy vehicles } \\
\text { 4) Volume of passenger cars }\end{array}$ & 500 & 0.73 \\
\hline 5 & Volume of light non-passenger car vehicles & 5 & 0.51 \\
\hline 6 & Volume of heavy vehicles & 5 & 0.46 \\
\hline 7 & Volume of passenger cars & 5 & 0.47 \\
\hline 8 & $\begin{array}{l}\text { 1) Speed } \\
\text { 2) Volume of heavy vehicles }\end{array}$ & 20 & 0.56 \\
\hline 9 & $\begin{array}{l}\text { 1) Speed } \\
\text { 2) Volume of passenger cars }\end{array}$ & 20 & 0.58 \\
\hline 10 & $\begin{array}{l}\text { 1) Speed } \\
\text { 2) Volume of light non-passenger car vehicles } \\
\text { 3) Volume of passenger cars }\end{array}$ & 100 & 0.7 \\
\hline
\end{tabular}


So the predicted number of property accidents is calculated by the model as in Figure 8.

The diagrams in rows 1 up to 4 in Figure 8 represent applying the first up to forth rule, as is seen the method of minimum is used to combine the diagrams, next the combined diagrams in four rows are aggregated to obtain the diagram in fifth row. In this diagram 0.82 is sum of 0.5 and 0.32 that are degrees of membership in combination (on the rightmost) diagrams in rows 1 and 2 respectively for 6 property accidents. 1.02 is sum of 0.7 and 0.32 that are degrees of membership in combination diagrams in rows 1 and 2 respectively for 8 property accidents. 1.46 is sum of $0.6,0.32,0.27$ and 0.27 that are degrees of membership in combination diagrams in rows 1 up to 4 respectively for 10 property accidents. 0.94 is sum of $0.2,0.2,0.27$ and 0.27 that are degrees of membership in combination diagrams in rows 1 up to 4 respectively for 12 property accidents.
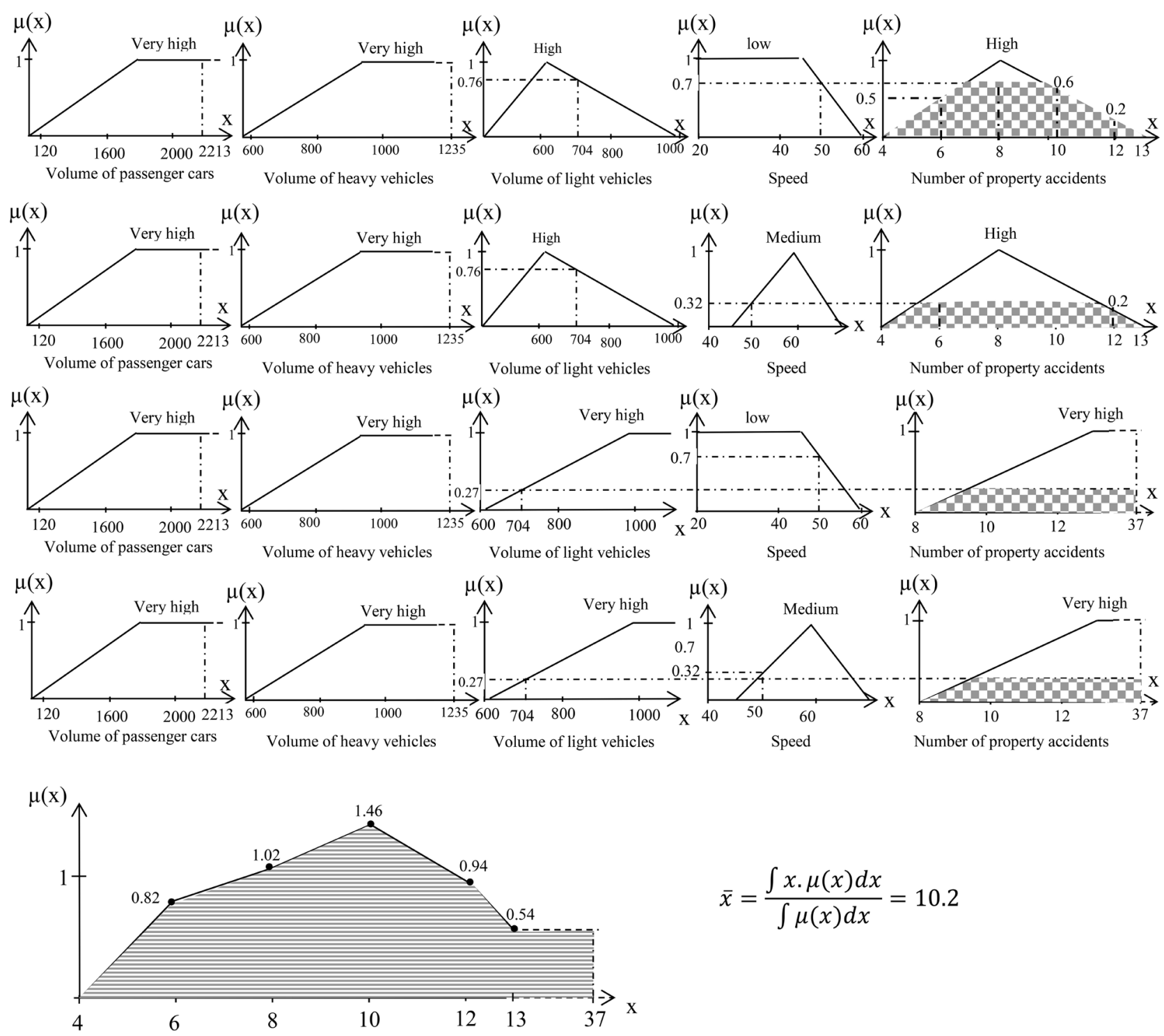

$$
\bar{x}=\frac{\int x \cdot \mu(x) d x}{\int \mu(x) d x}=10.2
$$

Figure 8. Calculation of predicted number of property accidents by the model. 
0.54 is sum of 0.27 and 0.27 that are degrees of membership in combination diagrams in rows 3 and 4 respectively for 13 to 37 property accidents. 37 is the maximum number of property accidents observed in Figure 1(e). The predicted number of property accidents by the model is obtained in defuzzification in which the method of centroid is used. The calculated value is equal to 10.2 which fits good with the observed number of property accidents equal to 12 according to scatter diagram in Figure 1(e). However the goodness of fit of the model is evaluated for all 300 data set in total in Figure 10.

2) For the 95-th data, according to scatter diagrams in Figure 1, the volume of passenger cars is $748 \mathrm{pc} / \mathrm{h}$, volume of heavy vehicles is $405 \mathrm{pc} / \mathrm{h}$, volume of light non-passenger car vehicles is $453 \mathrm{pc} / \mathrm{h}$ and speed is $50 \mathrm{~km} / \mathrm{h}$. Based on fuzzification diagrams of input variables in Figures 2-5, volume of passenger cars and heavy vehicles is low/medium, while volume of light non-passenger car vehicles is medium/high and speed is low/medium. If input variables speed and volume of heavy vehicles are considered effective (increasingly) in occurrence of more severe accidents as for case 8 in Table 3 following rules are producible:

a) If volume of heavy vehicles is low and speed is low, the number of more severe accidents is low.

b) If volume of heavy vehicles is low and speed is medium, the number of more severe accidents is low (or medium).

c) If volume of heavy vehicles is medium and speed is low, the number of more severe accidents is medium (or low).

d) If volume of heavy vehicles is medium and speed is medium, the number of more severe accidents is medium.

Based on the produced rules, the predicted number of more severe accidents is calculated by as in Figure 9.

As previous, diagrams in rows 1 up to 4 represent applying the first up to forth rule and method of minimum is used to combine the diagrams, next the combined diagrams in four rows are aggregated to obtain the diagram in fifth row. In this diagram 0.28 is sum of 0.14 and 0.14 that are degrees of membership in combination diagrams in rows 1 and 2 respectively for 0 more severe accidents. 1.02 is sum of 0.7 and 0.32 that are degrees of membership in combination diagrams in rows 3 and 4 respectively for 1 more severe accidents. Note that as the volume of passenger cars and light non-passenger car vehicles were considered not to be effective in occurrence of more severe accidents (in this specific case), these two variables do not have role in producing rules and hence do not cooperate in calculating the predicted number of more severe accidents.

The predicted number of more severe accidents by the model is obtained in defuzzification by method of centroid. The calculated value is equal to 0.95 which fits pretty good with the observed number of more severe accidents equal to 1 according to scatter diagram in Figure 1(f). However the goodness of fit of the model is evaluated for all 300 data set together in Figure 11. 

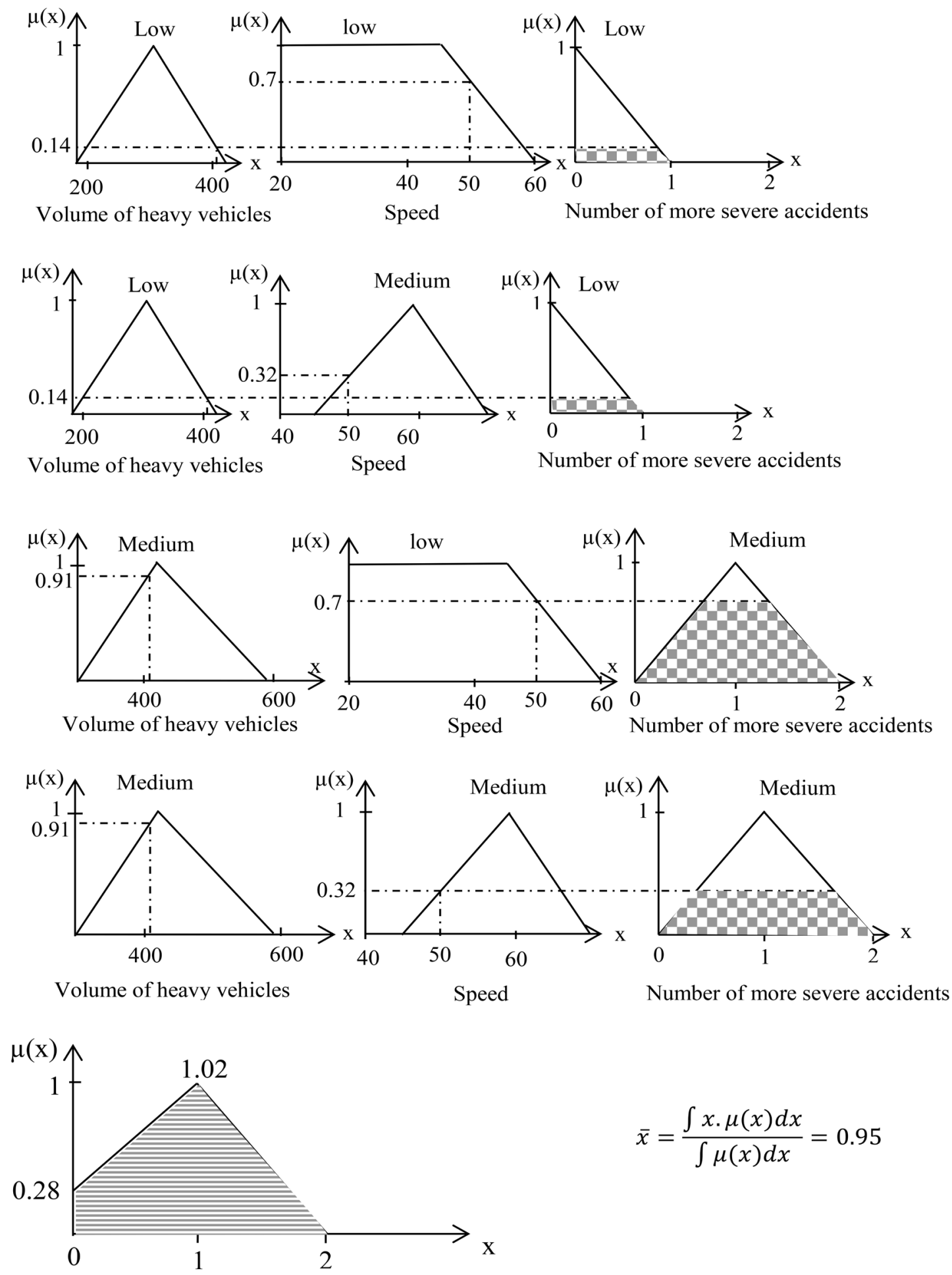

Figure 9. Calculation of predicted number of more severe accidents by the model.

In this research, first the variable speed is considered as the only effective variable on the occurrence of accidents, whether property or more severe accidents. Then rules are produced according to the effect of the variable considered effective, composition and aggregating the diagrams and next, defuzzification 
gives the crisp output which is the predicted number of accidents for each input data set. If the result of comparison between the numbers of predicted and observed accidents gives the value of $R^{2}$ bigger than 0.5 , proves the significance of variable speed in accident occurrence, otherwise the variable should be replaced by other one and the operation is done as previous.

In the next step, the variable volume of light non-passenger car vehicles is added to speed, the corresponding rules, for their direct effect on the number of property and more severe accidents in two individual models, are produced and at last defuzzification give the crisp predicted number of accidents for each input data set. If the value of $R^{2}$, result of comparison between the numbers of predicted and observed accidents is significantly bigger than previous, the influence of variable volume of light non-passenger car vehicles on accident occurrence is confirmed, otherwise the variable is replaced and the process is repeated.

This procedure is continued since the best composition of effective variables with the highest related value of $R^{2}$ is identified.

The cases of fuzzy modeling including the considered effective factors, number of produced rules and $R^{2}$ value come in Table 2 and Table 3 for property and more severe accidents respectively. The indicator diagram which illustrates the comparison of observed and evaluated number of accidents for the case with highest value of $R^{2}$ comes after the tables in Figure 10 and Figure 11 for property and more severe accidents respectively.

Table 3. The prediction power of number of more severe accidents of different cases.

\begin{tabular}{|c|c|c|c|}
\hline Case & $\begin{array}{l}\text { Effective factors } \\
\text { (considered) }\end{array}$ & Number of rules & $\mathrm{R}^{2}$ \\
\hline 1 & Speed & 4 & 0.56 \\
\hline 2 & $\begin{array}{l}\text { 1) Speed } \\
\text { 2) volume of light non-passenger car vehicles }\end{array}$ & 20 & 0.65 \\
\hline 3 & $\begin{array}{l}\text { 1) Speed } \\
\text { 2) Volume of light non-passenger car vehicles } \\
\text { 3) Volume of heavy vehicles }\end{array}$ & 100 & 0.7 \\
\hline 4 & $\begin{array}{l}\text { 1) Speed } \\
\text { 2) Volume of light non-passenger car vehicles } \\
\text { 3) Volume of heavy vehicles } \\
\text { 4) Volume of passenger cars }\end{array}$ & 500 & 0.72 \\
\hline 5 & Volume of light non-passenger car vehicles & 5 & 0.48 \\
\hline 6 & Volume of heavy vehicles & 5 & 0.42 \\
\hline 7 & Volume of passenger cars & 5 & 0.45 \\
\hline 8 & $\begin{array}{l}\text { 1) Speed } \\
\text { 2) Volume of heavy vehicles }\end{array}$ & 20 & 0.62 \\
\hline 9 & $\begin{array}{l}\text { 1) Speed } \\
\text { 2) Volume of passenger cars }\end{array}$ & 20 & 0.58 \\
\hline 10 & $\begin{array}{l}\text { 1) Speed } \\
\text { 2) Volume of light non-passenger car vehicles } \\
\text { 3) Volume of passenger cars }\end{array}$ & 100 & 0.67 \\
\hline
\end{tabular}




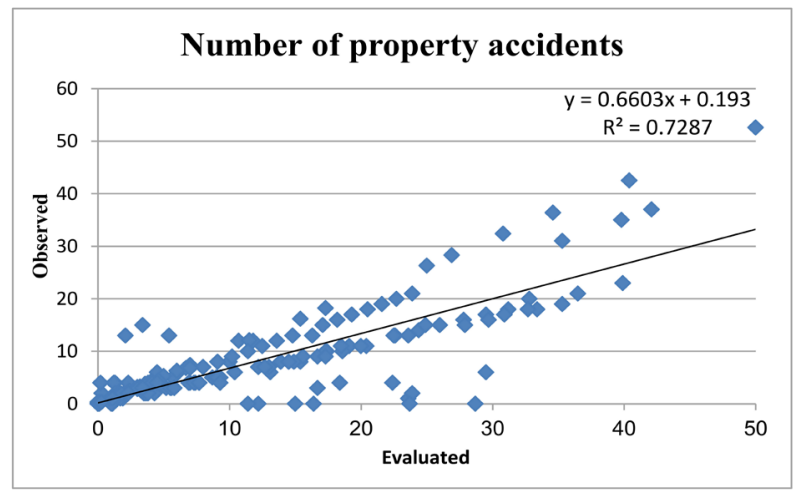

Figure 10. Comparison between the evaluated and observed number of property accident for case 4 .

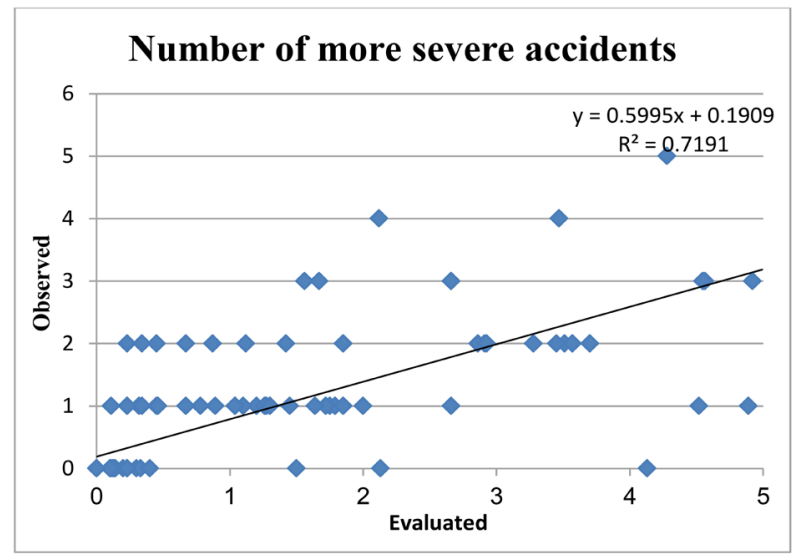

Figure 11. Comparison between the evaluated and observed number of more severe accidents for case 4 .

\section{Sensitivity Analysis and Discussion}

A the final part of this research is sensitivity analysis in which the impact rate of each variable on occurrence of no injury and more severe accidents on urban highways is determined. To do this the best models which presented the most accurate results for no injury and more severe accidents are applied. According to Table 2 and Table 3 or Figure 10 and Figure 11, the most accurate models for predicting the number of property and more severe accidents is case 4 with goodness of fit equal to 0.73 and 072 respectively. To determine the impact rate of each variable on occurrence of accidents, the value of each variable in data set (300 data) is increased by one unit and the rate of change in the predicted number of accidents is investigated. As the average of speed, volume of light non passenger car vehicles, heavy vehicles and passenger cars in data set is 65, 630, 565 and 1095 respectively, it is more accurate to compare the effect of one unit increase in speed with 9.7, 8.7 and 16.8 unit increase in the value of light non passenger car vehicles, heavy vehicles and passenger cars respectively on likelihood of accidents. Clearly 9.7, 8.7 and 16.8 are equal to 630, 565 and 1095 divided by 65 respectively. 
Each data set comprises 300 data for each variable. The results of sensitivity Analysis for input variables of speed, volume of light non-passenger car vehicles, heavy vehicles and passenger cars are depicted in Figures 12-15. To measure the impact rate of each variable on likelihood of property and more severe accidents, the impact rate for all 300 data are averaged to determine the specific value. The specific values determined for all variables on occurrence of accidents on urban highways are presented for both property and more severe accidents in Table 4.

Table 4. Impact rate of input variables on occurrence of property and more severe accidents on urban highways.

\begin{tabular}{ccccc}
\hline $\begin{array}{c}\text { Impact rate of variables on } \\
\text { occurrence of accidents }\end{array}$ & Speed & $\begin{array}{c}\text { Volume of light non } \\
\text { passenger car vehicles }\end{array}$ & $\begin{array}{c}\text { Volume of heavy } \\
\text { vehicles }\end{array}$ & $\begin{array}{c}\text { Volume of } \\
\text { passenger cars }\end{array}$ \\
\hline Property accidents & 0.31 & 0.25 & 0.18 & 0.21 \\
More severe accidents & 0.052 & 0.046 & 0.034 & 0.03 \\
\hline
\end{tabular}

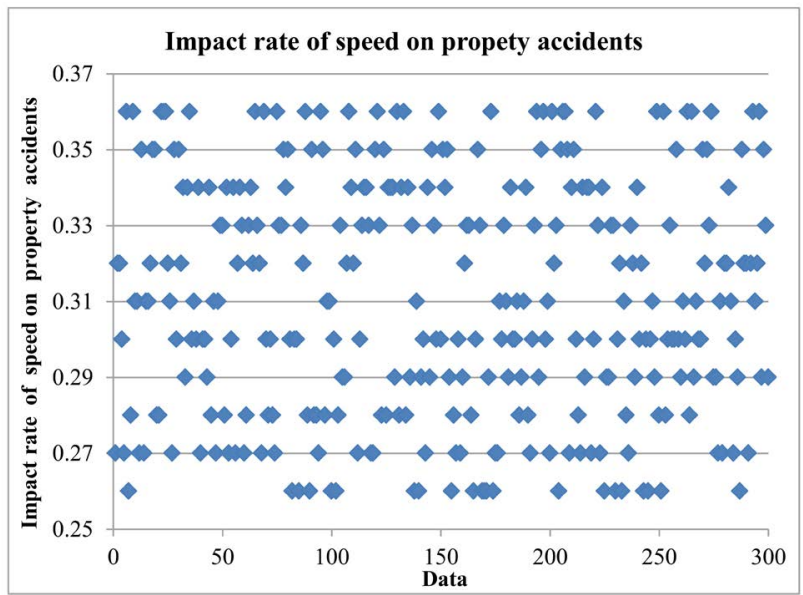

(a)

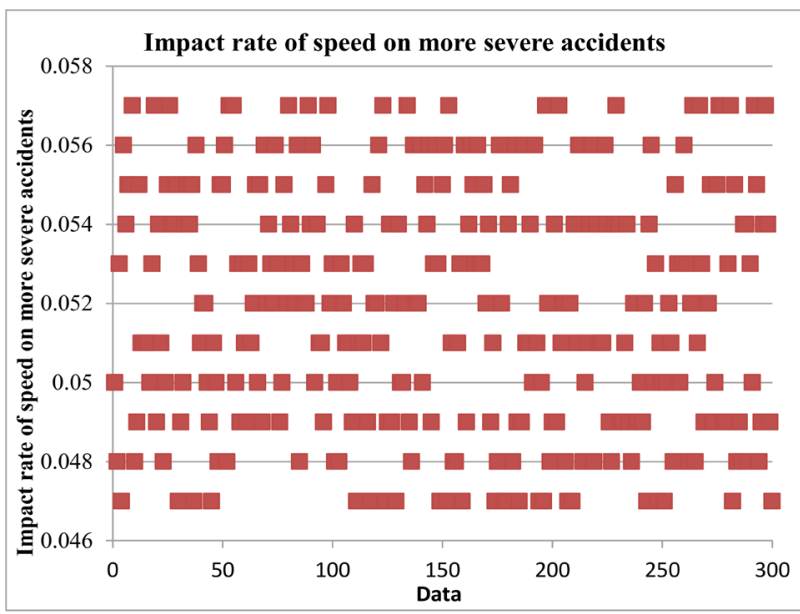

(b)

Figure 12. Impact rate of speed on likelihood of accidents on urban highways. (a) Impact rate of speed on likelihood of property accidents; (b) Impact rate of speed on likelihood of more severe accidents. 


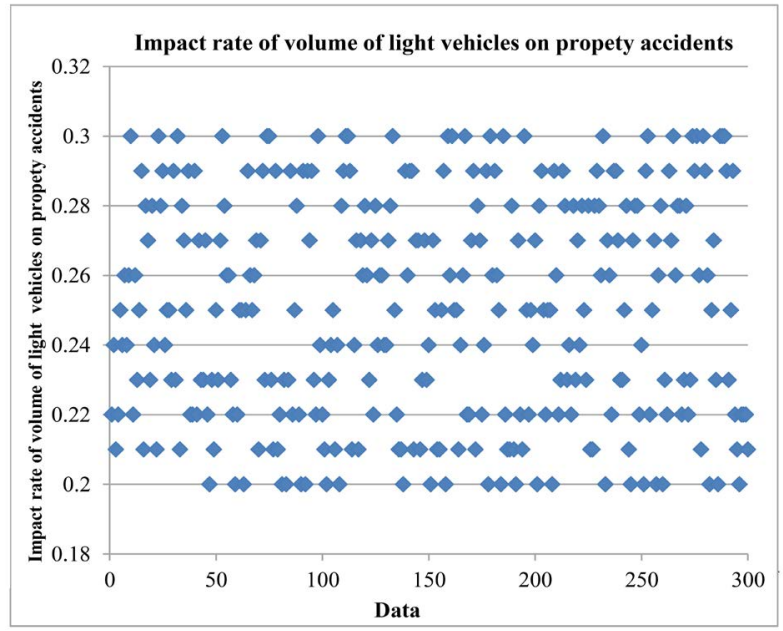

(a)

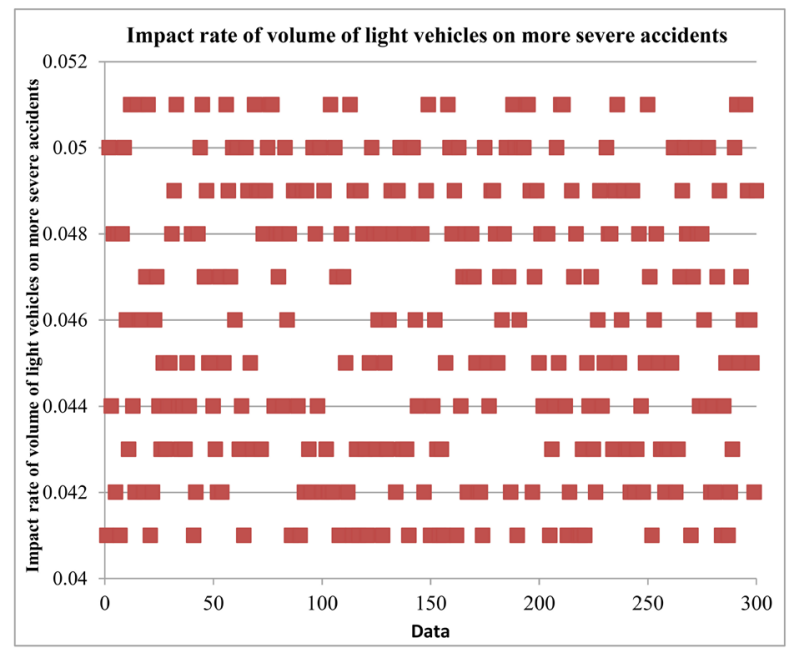

(b)

Figure 13. Impact rate of volume of light non passenger car vehicles on likelihood of accidents on urban highways. (a) Impact rate of volume of light non passenger car vehicles on likelihood of property accidents; (b) Impact rate of volume of light non passenger car vehicles on likelihood of more severe accidents.

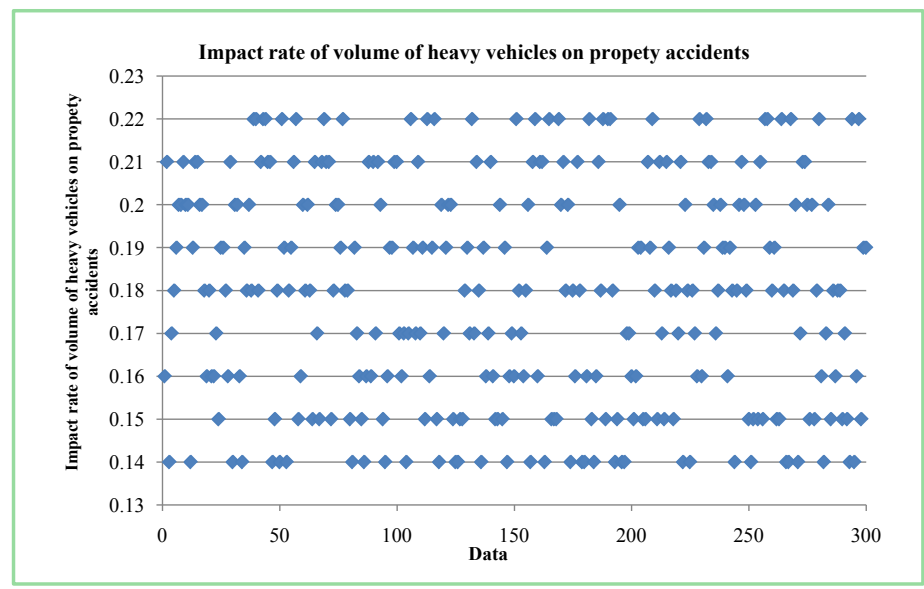

(a) 


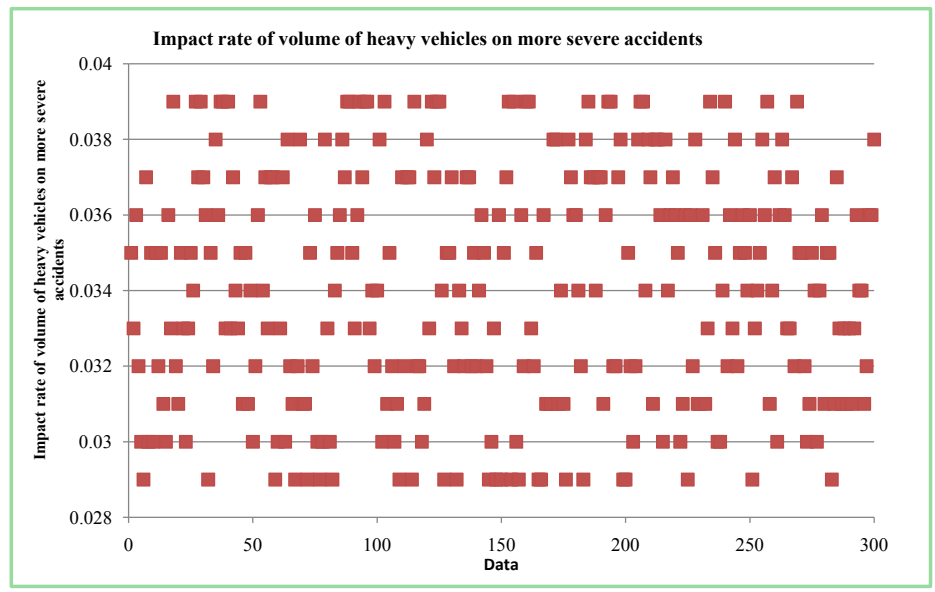

(b)

Figure 14. Impact rate of volume of heavy vehicles on likelihood of accidents on urban highways. (a) Impact rate of volume of heavy vehicles on likelihood of property accidents; (b) Impact rate of volume of heavy vehicles on likelihood of more severe accidents.

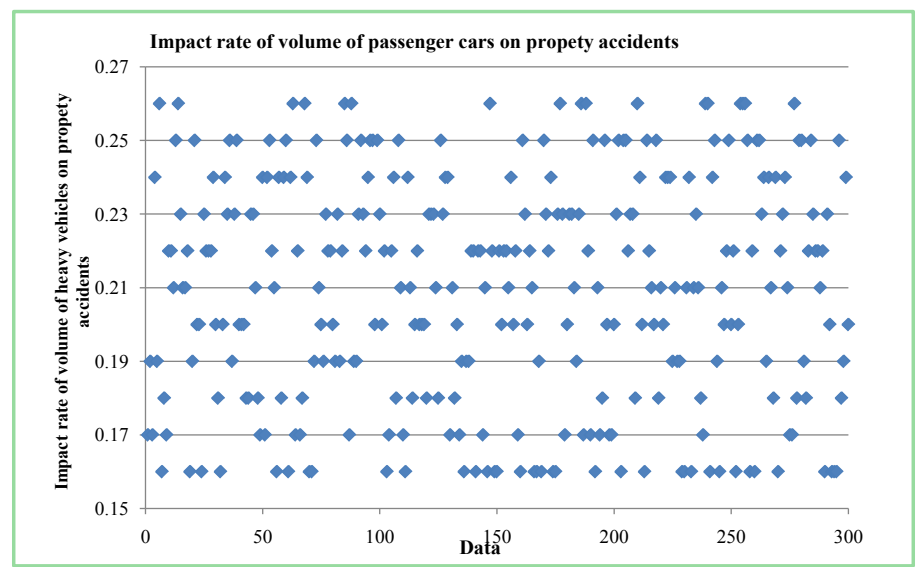

(a)

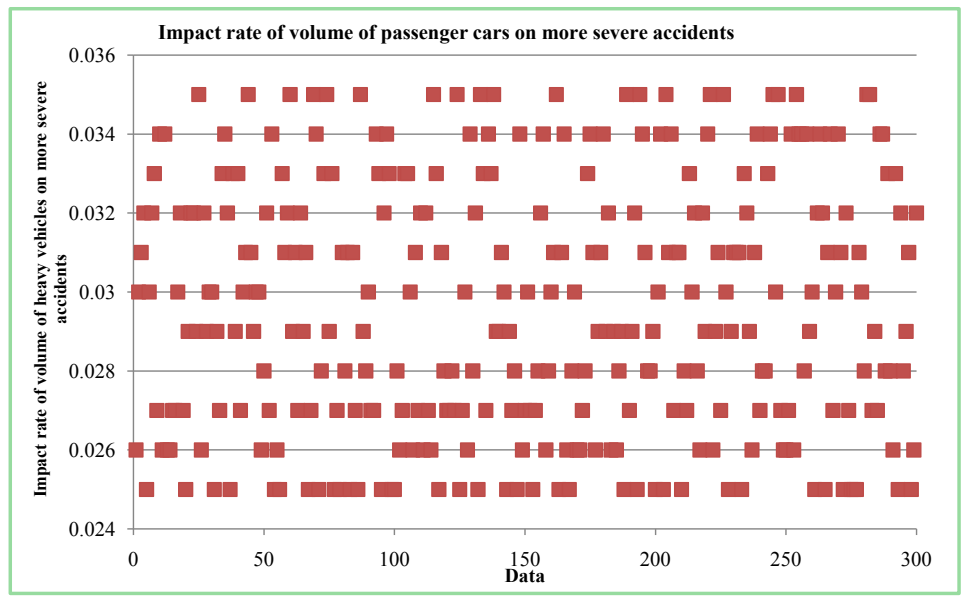

(b)

Figure 15. Impact rate of volume of passenger cars on likelihood of accidents on urban highways. (a) Impact rate of volume of passenger cars on likelihood of property accidents; (b) Impact rate of volume of passenger cars on likelihood of more severe accidents. 
As shown in Table 4, the impact rate of speed on occurrence of property and more severe accidents on urban highways is equal to 0.31 and 0.052 respectively. It indicates that when the value of speed increases by one unit, for example from $58 \mathrm{~km} / \mathrm{h}$ to $59 \mathrm{~km} / \mathrm{h}$, the number of property accidents is increased by 0.31 unit and more severe accidents by 0.052 unit or more clearly when the moving speed is increased by ten units, for example from $58 \mathrm{~km} / \mathrm{h}$ to $68 \mathrm{~km} / \mathrm{h}$, the number of property accidents is increased by about 3 units and more severe accidents by 0.5 unit. Then effect rate of the volume of light non passenger cars on occurrence of property and more severe accidents on urban highways is equal to 0.25 and 0.046 respectively. It represents that when the value of light non passenger cars is increased by 9.7 unit, for example from $605 \mathrm{pc} / \mathrm{h}$ to $614.7 \mathrm{pc} / \mathrm{h}$, the number of property accidents is increased by 0.25 unit and more severe accidents by 0.046 unit or more clearly when the volume of light non passenger cars is increased by 97 units, for example from $605 \mathrm{pc} / \mathrm{h}$ to $702 \mathrm{pc} / \mathrm{h}$, the number of property accidents is increased by 2.5 units and more severe accidents by about 0.5 unit. The impact rate of volume of heavy vehicles on likelihood of property and more severe accidents is 0.18 and 0.034 respectively. It implies that when volume of heavy vehicles is increased by 8.7 units, for example from 550 to 558.7 , number of property and more severe accidents increases 0.18 and 0.034 unit respectively on urban highways or more tangibly, if the volume of heavy vehicles is increased by 87 units, for example from 550 to 637 units, number of no injury and more severe accidents increases by about 2 units and 0.35 unit respectively. Finally the impact rate of volume of passenger cars on occurrence of property and more severe accidents is 0.21 and 0.03 respectively. It indicates that if the number of passenger cars in traffic flow of urban highway is increased by 16.8 units in an hour, the number of no injury and more severe accidents increases by 0.21 and 0.03 units respectively. More tangibly, when the volume of passenger cars is increased by 168 units, for example from $1105 \mathrm{pc} / \mathrm{h}$ to $1273 \mathrm{pc} / \mathrm{h}$, the number of property and more severe accidents increases by about 2 and 0.3 units respectively.

In addition to sensitivity analysis, the values of impact rate in Table 4 confirm the prioritization of variables in terms of their measure of influence on occurrence of property and more severe accidents. It is clear that speed have the most influence on likelihood of accidents in comparison with volume of passenger cars $(0.21,0.03)$, heavy vehicles $(0.18,0.034)$ and light non passenger car vehicles $(0.25,0.046)$ because of the bigger value of effect rate $(0.31,0.052)$. After that, volume of light non passenger car vehicles is more influential in occurrence of accidents on urban highways whether property or more severe accidents. Then volume of heavy vehicles is more effective on occurrence of more severe accidents than volume of passenger cars. But the volume of passenger cars is more influential than heavy vehicles in occurrence of property accidents. It is noteworthy to remind that the average of speed, volume of light non passenger car vehicles, heavy vehicles and passenger cars in data set is 65, 630, 565 and 1095 
respectively. Therefore it is logical to compare the effect of one unit increase in speed with 9.7, 8.7 and 16.8 unit increase in the value of light non passenger car vehicles, heavy vehicles and passenger cars respectively on likelihood of accidents. Where 9.7, 8.7 and 16.8 are equal to 630,565 and 1095 divided by 65 respectively.

\section{Conclusions}

In this research, two fuzzy logic based models for predicting the number of property and more severe accidents on urban highways are presented. After developing the models for predicting the number of accidents on urban highways, the predicted number of property and more severe accidents by the models are compared with the number of observed accidents for each case i.e. specific combination of effective factors. The results of comparison show the accuracy of each model which is developed based on the role of variables that considered effectively in occurrence of property or more severe accidents individually. The model with the highest value of $R^{2}$, the goodness of fit, is the best model.

The results of research indicate that when speed, volume of light non-passenger car vehicles, volume of heavy vehicles and volume of passenger cars are considered to directly affect the frequency of accidents, the produced rules result in the model which predicts the number of accidents most accurately with $R^{2}=$ 0.73 and $R^{2}=0.72$ for property and more severe accidents respectively; this indicates that all the variables under study play a role in the likelihood of property accidents. The complemental results showed that the role of average speed is more prominent than the volume elements of traffic in the likelihood of both property and more sever accidents. This is concluded when the value of $\mathrm{R}^{2}$ for case 1 is compared to that for cases 5, 6 and 7. After speed, the variable volume of light non-passenger car vehicles is identified to play a more effective role than the volume of heavy vehicles and passenger cars in the likelihood of accidents, whether property or more severe accidents. This is concluded when the value of $\mathrm{R}^{2}$ for case 2 is compared to that for cases 8 and 9 . Finally the role of heavy vehicles is more influential in occurrence of more severe accidents than passenger cars, while the opposite is true for property accidents. This is clear when the value of $\mathrm{R}^{2}$ for cases 3 and 10 is compared together.

After prioritization of variables in terms of influence on occurrence of accidents, the models best fitting the data with the highest value of goodness of fit were employed to do the sensitivity analyse. Sensitivity analyse specifies the effect rate of each variable on likelihood of accidents. The results of sensitivity analysis indicated that the impact rate of speed on occurrence of property and more severe accidents on urban highways is equal to 0.31 and 0.052 respectively. It indicates that when the value of speed increases by one unit, the number of property accidents is increased by 0.31 unit and more severe accidents by 0.052 units. The effect rate of the volume of light non passenger cars on occurrence of property and more severe accidents on urban highways is equal to 0.25 and 
0.046 respectively. It represents that when the value of light non passenger cars is increased by 9.7 units, the number of property accidents is increased by 0.25 unit and more severe accidents by 0.046 units. The impact rate of volume of heavy vehicles on likelihood of property and more severe accidents is 0.18 and 0.034 respectively. It implies that when volume of heavy vehicles is increased by 8.7 units, number of property and more severe accidents increases 0.18 and 0.034 unit respectively. Finally the impact rate of volume of passenger cars on occurrence of property and more severe accidents is 0.21 and 0.03 respectively. It implies that when the number of passenger cars in traffic flow of urban highway is increased by 16.8 units in an hour, the number of no injury and more severe accidents increases by 0.21 and 0.03 units respectively.

\section{Conflicts of Interest}

The authors declare no conflicts of interest regarding the publication of this paper.

\section{References}

[1] Chen, S., Chen, F. and Wu, J. (2011) Multi-Scale Traffic Safety and Operational Performance Study of Large Trucks on Mountainous Interstate Highway. Accident Analysis and Prevention, 43, 429-438. https://doi.org/10.1016/j.aap.2010.09.013

[2] Ayati, E. and Abbasi, E. (2011) Investigation on the Role of Traffic Volume in Crashes on Urban Highways. Safety Research, 42, 209-214.

https://doi.org/10.1016/j.jsr.2011.03.006

[3] Kaplan, S. and Prato, C.G. (2012) Risk Factors Associated with Bus Accident Severity in the United States: A Generalized Ordered Logit Model. Journal of Safety Research, 43, 171-180. https://doi.org/10.1016/j.jsr.2012.05.003

[4] Chang, L. and Chien, J. (2013) Analysis of Driver Injury Severity in Truck-Involved Crashes Using a Non-Parametric Classification Tree Model. Safety Science, 51, 17-22. https://doi.org/10.1016/j.ssci.2012.06.017

[5] Feng, Sh., Zhang, G., et al. (2016) Risk Factors Affecting Fatal Bus Accident Severity: Their Impact on Different Types of Bus Drivers. Accident Analysis and Prevention, 86, 29-39. https://doi.org/10.1016/j.aap.2015.09.025

[6] Green, C.P., Heywood, J.S. and Navarro, M. (2016) Traffic Crashes and the London Congestion Charge. Journal of Public Economics, 133, 11-22.

https://doi.org/10.1016/j.jpubeco.2015.10.005

[7] Castillo-Manzano, J.I., Castro-Nuño, M. and Fageda, X. (2016) Exploring the Relationship between Truck Load Capacity and Traffic Crashes in the European Union. Transportation Research Part E, 88, 94-109.

https://doi.org/10.1016/j.tre.2016.02.003

[8] Tseng, C.-M., Yeh, M.-S., Tseng, L.-Y., Liu, H.-H. and Lee, M.-C. (2016) A Comprehensive Analysis of Factors Leading to Speeding Offenses among Large-Truck Drivers. Transportation Research Part F, 38, 171-181. https://doi.org/10.1016/j.trf.2016.02.007

[9] Cerezoa, V. and Conche, F. (2016) Risk Assessment in Ramps for Heavy Vehicles-A French Study. Accident Analysis and Prevention, 91, 183-189. https://doi.org/10.1016/j.aap.2016.02.017 
[10] Goh, K., Currie, G., Sarvi, M. and Logan, D. (2014) Factors Affecting the Probability of Bus Drivers Being At-Fault in Bus-Involved Crashes. Accident Analysis and Prevention, 66, 20-26. https://doi.org/10.1016/j.aap.2013.12.022

[11] Grytnes, R., Shibuya, H., Dyreborg, J., Grøn, S. and Cleal, B. (2016) Too Individualistic for Safety Culture? Non-Traffic Related Work Safety among Heavy Goods Vehicle Drivers. Transportation Research Part F, 40, 145-155. https://doi.org/10.1016/j.trf.2016.04.012

[12] Evgenikos, P., Yannis, G., Folla, K., Bauer, R., Machata, K. and Brandstaetter, C. (2016) Characteristics and Causes of Heavy Goods Vehicles and Buses Accidents in Europe. Transportation Research Procedia, 14, 2158-2167. https://doi.org/10.1016/j.trpro.2016.05.231

[13] Boyce, W.S. (2016) Does Truck Driver Health and Wellness Deserve More Attention? Journal of Transport \& Health, 3, 124-128. https://doi.org/10.1016/j.jth.2016.02.001

[14] Zhu, X. and Srinivasan, S. (2011) Modeling Occupant-Level Injury Severity: An Application to Large-Truck Crashes. Accident Analysis and Prevention, 43, 1427-1437. https://doi.org/10.1016/j.aap.2011.02.021

[15] Abdelwahab, H. and Abdel-Aty, M. (2004) Investigating the Effect of Light Truck Vehicle Percentages on Head-On Fatal Traffic Crashes. Journal of Transportation Engineering, 130, 429-437. https://doi.org/10.1061/(ASCE)0733-947X(2004)130:4(429)

[16] Daniel, J. and Chien, S.I.-J. (2004) Truck Safety Factors on Urban Arterials. Journal of Transportation Engineering, 130, 742-752. https://doi.org/10.1061/(ASCE)0733-947X(2004)130:6(742)

[17] Mohamed, N., Mohd-Yusoff, M.-F., Othman, I., Zulkipli, Z.-H., Osman, M.R. and Voon, W.S. (2012) Fatigue-Related Crashes Involving Express Buses in Malaysia: Will the Proposed Policy of Banning the Early-Hour Operation Reduce Fatigue-Related Crashes and Benefit Overall Road Safety? Accident Analysis \& Prevention, 45, 45-49. https://doi.org/10.1016/j.aap.2011.09.025

[18] Edwards, J.R.D., Davey, J. and Armstrong, A.K. (2014) Profiling Contextual Factors Which Influence Safety in Heavy Vehicle Industries. Accident Analysis and Prevention, 73, 340-350. https://doi.org/10.1016/j.aap.2014.09.003

[19] Hosseinpour, M., Yahaya, A.S. and Sadullah, A.F. (2014) Exploring the Effects of Roadway Characteristics on the Frequency and Severity of Head-On Accidents: Case Studies from Malaysian Federal. Accident Analysis and Prevention, 16, 209-222. https://doi.org/10.1016/j.aap.2013.10.001

[20] Mussonea, S., Bassanib, M. and Mascib, P. (2017) Analysis of Factors Affecting the Severity of Accidents in Urban Road Intersections. Accident Analysis \& Prevention, 103, 112-122. https://doi.org/10.1016/j.aap.2017.04.007

[21] Ruslia, R., Haquea, M.M., King, M. and Voon, W.S. (2017) Single-Vehicle Crashes along Rural Mountainous Highways in Malaysia: An Application of Random Parameters Negative Binomial Model. Accident Analysis and Prevention, 102, 153-164. https://doi.org/10.1016/j.aap.2017.03.002

[22] Mallia, L., Lazuras, L., Violani, C. and Lucidi, F. (2015) Crash Risk and Aberrant Driving Behaviors among Bus Drivers: The Role of Personality and Attitudes towards Traffic Safety. Accident Analysis and Prevention, 79, 145-151. https://doi.org/10.1016/j.aap.2015.03.034

[23] Fowles, R., Loeb, P.D. and Clarke, W. (2013) The Cell Phone Effect on Truck Crashes: A Specification Error Approach. Transportation Research Part E, 50, 
18-28. https://doi.org/10.1016/j.tre.2012.10.002

[24] Chen, G.X., Fang, Y., Guo, F. and Hanowski, R.J. (2016) The Influence of Daily Sleep Patterns of Commercial Truck Drivers Ondriving Performance. Accident Analysis and Prevention, 91, 55-63. https://doi.org/10.1016/j.aap.2016.02.027

[25] Najafi, Sh., Flintsch, G.W. and Khaleghian, S. (2016) Fuzzy Logic Inference-Based Pavement Friction Management and Real-Time Slippery Warning Systems: A Proof of Concept Study. Accident Analysis and Prevention, 90, 41-49. https://doi.org/10.1016/j.aap.2016.02.007

[26] Traffic and Transportation Organization of Tehran Municipality, Iran (2014) Comprehensive Studies of Transportation Office. Forth Statistical Paper of Transportation of Tehran. 